PROC. OF JSCE,

No. 268, DEC. 1977

\title{
ESTIMATION OF LIFE OF RIPPERTIP DUE TO WEAR
}

\author{
By Shōjirō HATA*, Tatsurō MURO ${ }^{* *}$ and Yoshinobu KANEKO***
}

\section{INTRODUCTION}

One of the most important problems in mechanical excavation of rock mass by means of ripping operations is to estimate precisely the life of tip due to wear and to establish the reasonable plan for excavation work based on fair judgements. The ability of excavation of rippertip against rock mass has already been evaluated by means of its longitudinal elastic wave velocity ${ }^{1)}$. But, the hardness or ease of ripping operation for rock mass must be considered to be determined not only by maximum power of excavation of bulldozer but also by the life of tip due to wear. So far, we have studied about the characteristics of shape variation of

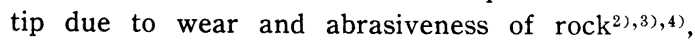
and about correlations between several properties of rock $^{5}$.

Here, the wear life of rippertip excavating several rock masses has been analysed. For this purpose, 11 series of wear tests of tip were executed at the different ripping operation sites respectively. These ripping operation sites have been selected as comparatively severe wear zone for rippertip excavating rock mass. In these cases, all ripping operations were executed by the same kinds of bulldozer of which maximum traction forces were nearly equal to 30 ton and vehicle forms, types and weight were almost the same. In these field tests, the physical properties of rock mass were investigated, and the variation of amount of wear or wear length of tip were measured respectively for several ripping operation time. As the results, it has been cleared that the index of rock mass strength for wear which is determined by uniaxial compressive strength, coefficient of crack, hard rock forming minerals content, apparent specific gravity, amount of Los Angeles abrasion, absorption and Shore hard ness, determines the wear life of rippertip. And

* Professor, Dept. of Civil Eng., Kyōto Univ.

** Associate Professor, Dept. of General Constructive Eng., Fukui Univ.

*** Assistant, Dept. of Civil Eng., Kyōto Univ. the aim of this study is to determine the equations which estimate the wear life of rippertip.

\section{CHARACTERISTICS OF ROCK MASS}

In these 11 sites of ripping operations named $\mathrm{A}$, $B, C, \cdots$ and $K$, several in-situ tests for each rock mass were executed, and, at the same site, rock specimens were sampled for several laboratory rock tests. Table 1 shows these test results. As laboratory rock tests, apparent specific gravity $G$, specific gravity $G_{s}$, natural water content $W$, absorption $W^{\prime}$, uniaxial compressive strength $\sigma_{c o}$, Shore hardness $H_{s}$, amount of Los Angeles abrasion $U$, longitudinal elastic wave velocity $V_{1}$ and porosity $n_{1}$ of non-fissured rock sample were measured respectively. Each laboratory test was executed for nonfissured rock sample in which any crack or fissure is not observed with the naked eye. The amount of Los Angeles abrasion was measured by means of the method prescribed in JIS A 1121 for 12 steel balls, about $8000 \mathrm{~g}$ rock block specimens, and the number of rotations 1000 . The porosity of rock specimen $n_{1}$ was calculated as $n_{1}=\left(G_{s}-G\right) / G_{s}$, that is, the porosity of the inner parts of rock which is entirely isolated from the outside world is also calculated. As in-situ test of rock mass, longitudinal elastic wave velocity of rock mass $V_{2}$ was measured. Then the coefficient of crack of rock mass $C_{r}{ }^{6)}$ was calculated by use of Eq. (1), from $V_{2}$ for fissured rock mass and $V_{1}$ for non-fissured rock specimen.

$$
C_{r}=1-\left(V_{2} / V_{1}\right)^{2}
$$

And, the other method of quantification of discontinuities of rock and rock mass is proposed by Fourmaintraux. $D^{7)}$ as “Rock Quality Index $I Q$ " which is defined from the longitudinal elastic wave velocity measurements $V_{L M}$ in rock sample or rock mass devided by the elastic wave velocity $V_{L C}$ calculated from several experimental data. It makes possible the detection, quantification and description of discontinuities of rock or rock mass as shown in Eq. (2).

$$
I Q(\%)=\left(V_{L M} / V_{L C}\right) \times 100
$$


Table 1 Physical properties of rock mass and rock specimen.

\begin{tabular}{|c|c|c|c|c|c|c|c|c|c|c|c|}
\hline Site of Sampling & A & $\mathrm{B}$ & $\mathrm{C}$ & $\mathrm{D}$ & $\mathrm{E}$ & $\mathrm{F}$ & G & $\mathrm{H}$ & I & $\mathrm{J}$ & $\mathrm{K}$ \\
\hline Name of Rock & $\begin{array}{l}\text { Clay- } \\
\text { Slate }\end{array}$ & $\begin{array}{l}\text { Horn- } \\
\text { blende } \\
\text { Gabbro }\end{array}$ & Shale & $\begin{array}{l}\text { Serpen- } \\
\text { tine }\end{array}$ & $\begin{array}{l}\text { Sand } \\
\text { Stone }\end{array}$ & $\begin{array}{l}\mathrm{Me}^{+} \mathrm{a}- \\
\text { morphic } \\
\text { Andesite }\end{array}$ & Chert & $\begin{array}{l}\text { Sandy } \\
\text { Clay } \\
\text { Slate }\end{array}$ & $\begin{array}{l}\text { Gra- } \\
\text { nite }\end{array}$ & Chert & $\begin{array}{l}\text { Clay } \\
\text { Slate }\end{array}$ \\
\hline Apparent Specific Gravity $G$ & 1.85 & 2.86 & 2.63 & 2.61 & 2.53 & 2.58 & 2.55 & 2.32 & 2.59 & 2.61 & 2.00 \\
\hline Specific Gravity $G_{s}$ & 2.62 & 2.89 & 2.73 & 2.67 & 2.61 & 2.63 & 2.65 & 2.47 & 2.63 & 2.64 & 2.23 \\
\hline Natural Water Content $W(\%)$ & 2.14 & 0.17 & 0.09 & 0.66 & 0.37 & 1.94 & 1.36 & 3.70 & 0.27 & 0.70 & 5.79 \\
\hline Absorption $\quad W^{\prime}(\%)$ & 1.50 & 0.89 & 1.44 & 1.96 & 2.75 & 3.08 & 2.84 & 9.13 & 0.81 & 0.89 & 18.25 \\
\hline $\begin{array}{l}\text { Uniaxial Compressive } \\
\text { Strength } \sigma_{c o}\left(\mathrm{~kg} / \mathrm{cm}^{2}\right)\end{array}$ & 192 & 1192 & 250 & 550 & 370 & 344 & 1114 & 81 & 840 & 736 & 120 \\
\hline Shore Hardness $\quad H_{s}$ & 21.9 & 76.6 & 96.2 & 71.2 & 82.4 & 48.9 & 91.4 & 8.5 & 83.3 & 87.8 & 30.2 \\
\hline $\begin{array}{l}\text { Amount of Los Angeles } \\
\text { Abrasion }\end{array}$ & 25.1 & 12.2 & 26.5 & 33.0 & 35.6 & 24.0 & 39.8 & 39.3 & 35.3 & 20.6 & 20.5 \\
\hline $\begin{array}{l}\text { Elastic Wave Velocity of Non- } \\
\text { fissured Rock Sample } V_{1}(\mathrm{~m} / \mathrm{sec})\end{array}$ & 750 & 2488 & 1500 & 2578 & 3840 & 3645 & 2868 & 1971 & 3679 & 3247 & 2475 \\
\hline $\begin{array}{l}\text { Elastic Wave Velocity of } \\
\text { Rock Mass } V_{2}(\mathrm{~m} / \mathrm{sec})\end{array}$ & 640 & 1093 & 950 & 2060 & 1143 & 1315 & 1494 & 1348 & 1743 & 1650 & 1125 \\
\hline Coefficient of Crack $\quad C_{r}$ & 0.272 & 0.807 & 0.599 & 0.362 & 0.911 & 0.870 & 0.729 & 0.532 & 0.776 & 0.742 & 0.793 \\
\hline $\begin{array}{l}\text { Rock Quality Index of Non- } \\
\text { fissured Rock Sample } I Q_{1}(\%)\end{array}$ & 52.96 & 98.35 & 94.14 & 96.42 & 95.10 & 96.96 & 93.84 & 90.29 & 97.57 & 98.42 & 83.47 \\
\hline $\begin{array}{l}\text { Rock Quality Index of } \\
\text { Rock Mass }\end{array}$ & 45.20 & 43.20 & 59.64 & 77.04 & 28.31 & 34.98 & 48.89 & 61.75 & 46.22 & 50.02 & 37.94 \\
\hline $\begin{array}{l}\text { Porosity of Non-fissured } \\
\text { Rock Sample }\end{array} n_{\mathrm{i}}(\%)$ & 29.40 & 1.03 & 3.66 & 2.24 & 3.06 & 1.90 & 3.85 & 6.07 & 1.52 & 0.99 & 10.33 \\
\hline Porosity of Rock Mass $n_{2}(\%)$ & 29.74 & 3.48 & 5.19 & 3.10 & 6.03 & 4.65 & 5.85 & 7.34 & 3.80 & 3.14 & 12.35 \\
\hline$K \cdot K_{0}^{2}$ Value & 0.464 & 0.414 & 0.262 & 0.177 & 0.473 & 0.474 & 0.991 & 0.131 & 0.691 & 1.591 & 0.179 \\
\hline $\begin{array}{l}\text { Index of Rock Mass Strength } \\
\text { for Wear } \sigma_{c}\left(\mathrm{~kg}^{/} \mathrm{cm}^{2}\right)\end{array}$ & 65 & 95 & 26 & 62 & 16 & 21 & 299 & 5 & 130 & 302 & 4 \\
\hline $\begin{array}{c}\text { Mineral Composition } \\
\text { Quartz } \\
\text { Orthoclase } \\
\text { Plagioclase } \\
\text { Mica } \\
\text { Groundmass } \\
\text { Olivine } \\
\text { Magnetite } \\
\text { Calcite } \\
\text { Chlorite } \\
\text { Amphibole } \\
\text { Detritus }\end{array}$ & $\begin{array}{c}38.0 \\
0 \\
62.0 \\
0 \\
0 \\
0 \\
0 \\
0 \\
0 \\
0 \\
0\end{array}$ & $\begin{array}{c}0 \\
0 \\
58.8 \\
3.3 \\
0 \\
0 \\
0 \\
0 \\
0 \\
37.9 \\
0\end{array}$ & $\begin{array}{c}4.1 \\
0 \\
0 \\
23.9 \\
37.2 \\
0 \\
4.7 \\
0 \\
30.1 \\
0 \\
0\end{array}$ & $\begin{array}{c}0.2 \\
0 \\
0 \\
0 \\
0 \\
82.1 \\
17.7 \\
0 \\
0 \\
0 \\
0\end{array}$ & $\begin{array}{c}31.0 \\
29.0 \\
2.0 \\
1.0 \\
23.0 \\
0 \\
0 \\
0 \\
0 \\
0 \\
14.0\end{array}$ & $\begin{array}{c}0 \\
0 \\
47.0 \\
0 \\
47.0 \\
0 \\
1.0 \\
0 \\
0 \\
0 \\
5.0\end{array}$ & $\begin{array}{c}18.0 \\
0 \\
0 \\
0 \\
82.0 \\
0 \\
0 \\
0 \\
0 \\
0 \\
0\end{array}$ & $\begin{array}{l}0.1 \\
0 \\
99.7 \\
0 \\
0 \\
0 \\
0.2 \\
0 \\
0 \\
0 \\
0\end{array}$ & $\begin{array}{c}41.9 \\
0.5 \\
54.6 \\
2.2 \\
0 \\
0 \\
0 \\
0.8 \\
0 \\
0 \\
0\end{array}$ & $\begin{array}{c}48.0 \\
0 \\
2.0 \\
0 \\
50.0 \\
0 \\
0 \\
0 \\
0 \\
0 \\
0\end{array}$ & $\begin{array}{c}0 \\
38.0 \\
62.0 \\
0 \\
0 \\
0 \\
0 \\
0 \\
0 \\
0 \\
0\end{array}$ \\
\hline
\end{tabular}

In general, the porosity $n$ of rock or rock mass consists of porosity of fissure $n_{f}$ and porosity of pore $n_{p}$. From several experimental relationships between total porosity $n$ and elastic wave velocity $V_{L}$ in porous rock or cracked rock, the elastic wave velocity $V_{L C}$ calculated for zero porosity of rock is determined. From Fourmaintraux Diagram, rock quality index $I Q_{1}$ for non-fissured rock sample is calculated by use of $n_{1}\left(=n_{p}, n_{f}=0\right)$, and rock quality index $I Q_{2}$ for fissured rock mass is also calculated by use of $V_{L C}$ and $V_{2}$. Then, the total porosity $n_{2}$ of fissured rock mass is determined by $n_{1}, I Q_{1}$ and $I Q_{2}$ as shown in Table 1 . Furthermore, the relations of rock quality index $I Q_{2}$ and total porosity $n_{2}$ of fissured rock mass $\mathrm{A}, \mathrm{B}, \mathrm{C}, \cdots$ and $\mathrm{K}$ are plotted in Fourmaintraux Diagram as shown in Fig. 1, and these points show the rock quality index, porosity of fissure and porosity of pore respectively.

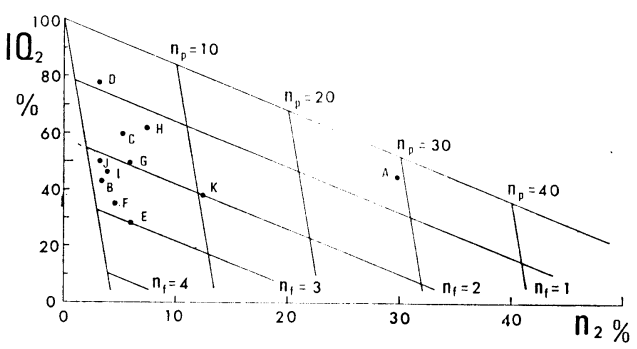

Fig. 1 Relations between rock quality index $I Q_{2}$ and porosity $n_{2}$ for fissured rock mass. 
Next, the mineral compositions were analysed for each rock specimen. The contents of quartz, orthoclase, plagioclase, mica etc. were measured by use of polarization microphotograph.

Now, the principal properties of rock mass which influence the amount of wear of rippertip are not evaluated by the compressive strength of rock specimen only, but they must be synthetically evaluated from several properties of rock mass. The degree of crack in rock mass, content of hard rock forming mineral, degree of weathering expressed by apparent specific gravity, amount of Los Angeles abrasion, absorption, and Shore hardness influence also the amount of wear of tip, even if the quality, size and shape of tip are the same.

Here, as an index which appreciates the strength of rock mass against wear of rippertip, "Index of Rock Mass Strength for Wear" $\sigma_{c}$ is defined as follows;

$$
\begin{aligned}
\sigma_{c} & =K \cdot K_{0}^{2} \sigma_{c o}\left(1-C_{r}\right) \\
K & =\frac{1}{4}\left(K_{1}+K_{2}+K_{3}+K_{4}\right)
\end{aligned}
$$

where $K_{0}=$ (Content of Quartz and Groundmass) $+($ Content of hard Feldspar etc. $) \times 0.5$ $\sigma_{c o}=$ Uniaxial compressive strength of nonfissured rock sample

$C_{r}=$ Coefficient of crack of rock mass

$K_{1}=$ (Apparent specific Gravity) $/ 2.60$

$K_{2}=30.0 /$ (Amount of Los Angeles Abrasion)

$K_{3}=2.00 /$ (Absorption)

$K_{4}=$ (Shore hardness) $/ 60.0$

This index of rock mass strength for wear has been given by product of independent factors which have been selected out of several properties of rock mass having important relations with the amount of wear of tip. That is, the amount of wear of tip is assumed to be proportional to the compressive strength of rock mass which is also assumed to be defined as $\sigma_{c o}\left(1-C_{r}\right)$ for fissured rock mass, because the amount of wear of metal is proportional to the contact pressure between metal and rock materials. And, the index of rock mass strength for wear is defined as product of the compressive strength and coefficient of modification $K \cdot K_{0}{ }^{2}$. Here, $1-\mathrm{C}_{r}=\left(V_{2} / V_{1}\right)^{2}$ means also that "Coefficient of damage of rock mass" $V_{2} / V_{1}{ }^{8}$ ) is more higher evaluated than the other factors. And, $K_{0}{ }^{2}$ means that the content of quartz, groundmass, and hard feldspar grains or other rock forming minerals of which hardness are larger than the hardness of rippertip is more higher evaluated, and $50 \%$ of the content of hard feldspar etc. is assumed to be contributed in the wear of tip, and $K$ is defined as an arithmetical average value of $K_{1}, K_{2}, K_{3}$ and $K_{4}$ as shown in Eq. (3). $K_{1}, K_{2}, K_{3}$ and $K_{4}$ is expressed by non-dimensional number. And each number $2.60,30.0,2.00$, and 60.0 , is given for wide range of rock properties by the average value of apparent specific gravity, amount of Los Angeles abrasion, absorption and Shore hardness, respectively. Furthermore, the dimension of $\sigma_{c}$ is the same as that of $\sigma_{c o}$ i.e. $\mathrm{kg} / \mathrm{cm}^{2}$. The value of $K \cdot K_{0}{ }^{2}$ and index of rock mass for wear $\sigma_{c}$ calculated from Eq. (3) for each site of ripping operation are shown in Table 1 respectively. And this equation of index of rock mass strength has been made by several trial and errors, but its expression is proved to be actually appropriate by the relation between amount of wear of rippertip and index of rock mass strength for wear as shown in later section.

\section{VARIATION OF WEAR AMOUNT AND WEAR LENGTH OF TIP}

All of the rippertips tested in the field of each site $A, B, C, \cdots$, and $K$ have the same size, shape and quality. Fig. 2 shows the size of tip, which is selected as generally used tip. The total length is $375 \mathrm{~mm}$, the width of pointed end is $88 \mathrm{~mm}$, and the initial weight is about $15 \mathrm{~kg}$. The average tensile strength of the material of tip is $156.5 \mathrm{~kg} /$ $\mathrm{mm}^{2}$, the elongation is $6.2 \%$, the contraction of area is $27.8 \%$, the Charpy impact value is $5.9 \mathrm{kgm} /$ $\mathrm{cm}^{2}$, the Vicker's hardness is $402 \pm 61.5$ and the Shore hardness is about 55.1. And the tip is constituted by specialized alloy steel with the chemical composition C: $0.27 \%, \mathrm{Si}: 0.29 \%, \mathrm{Mn}: 0.77 \%, \mathrm{P}$ : $0.018 \%, \mathrm{~S}: 0.018 \%, \mathrm{Ni}: 0.61 \%, \mathrm{Cr}: 0.51 \%$, and with a feathered structure of uniformly distributed fine carbide in a bainite modification.

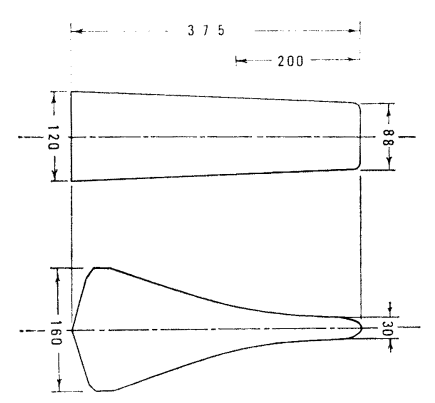

Fig. 2 Initial dimension and shape of rippertip.

The summarization of wear test results which the variations of wear length of tip with time were measured for each site of ripping operation is shown in Fig. 3. The wear length of pointed end of tip was measured by use of slide calipers as the 


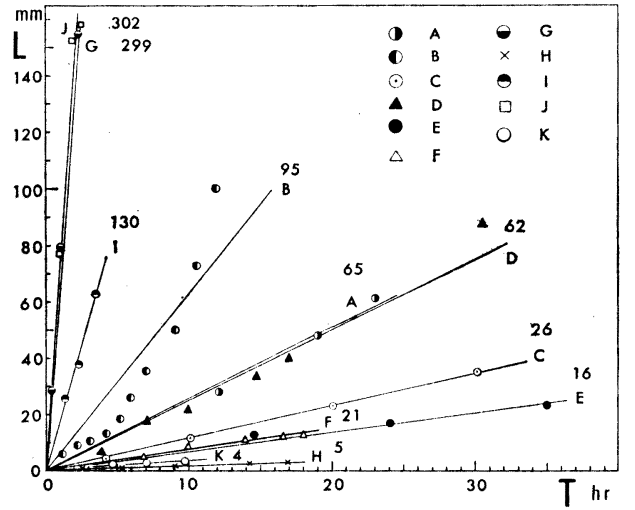

Fig. 3 Relations between wear length of pointed end of rippertip $L$ and ripping operation time $T$ (Numbers show $\sigma_{c}$ values).

difference between initial length and the measured length for each time. And the length of tip was measured along the central axis, from its fixed point to the end point. And, the ripping operation time showed in abscissa is the time required for practically reciprocating motion of bulldozer for ripping operation only, except for dozing or pushing operation, and was measured directly at each site by use of stop watch.

As shown in this figure, the variation of wear length is characterized respectively by the properties of rock mass. The higher the index of rock mass strength for wear, the greater the wear length of tip increases due to impact load acted on tip at the time of excavation. The variation of wear length of tip with ripping operation time disperses because the conditions of ripping operation are not constant for each site. But, it seems to be able to approximate some linear relationship between the wear length of tip $L$ and the ripping operation time $T$. Assuming that the linear equation $L=a T$ is formed, the most probable value of coefficient " $a$ " and coefficient of correlation " $r_{a}$ " are determined by means of principle of least squares, and are shown in Table 2.

Next, the wear amount of rippertip was measured precisely in the given field. Fig. 4 shows the summarization of wear test results. The variation of wear amount of rippertip with time were measured at the same time of measuring the wear length of pointed end of tip. These amount of wear are calculated as weight loss that is the difference between initial weight and the weight of tip which was measured for given operation time by means of removing it from bulldozer one by one. For measuring the weight loss of tip, a platform scale
Table 2 Most probable value of coefficient $a, b$ and coefficient of correlation $r_{a}, r_{b}$, for wear length $L=a T$ and amount of wear $M=b T$ respectively ( $T$ is ripping operation time).

\begin{tabular}{c|c|c|c|c}
\hline \multirow{2}{*}{ Site } & \multicolumn{2}{|c|}{$L(\mathrm{~mm})=a \cdot T(\mathrm{hr})$} & \multicolumn{2}{c}{$M(\mathrm{~g})=b \cdot T(\mathrm{hr})$} \\
\cline { 2 - 5 } & $a$ & $r_{a}$ & $b$ & $r_{b}$ \\
\hline A & 2.54 & 0.996 & 140.0 & 0.995 \\
\hline B & 6.32 & 0.945 & 278.7 & 0.983 \\
\hline C & 1.15 & 0.997 & 51.3 & 0.996 \\
\hline D & 2.52 & 0.973 & 119.5 & 0.994 \\
\hline E & 0.70 & 0.986 & 40.7 & 0.972 \\
\hline F & 0.73 & 0.990 & 46.7 & 0.906 \\
\hline G & 67.90 & 0.997 & 2965.1 & 0.996 \\
\hline H & 0.20 & 0.974 & 29.0 & 0.981 \\
\hline I & 17.93 & 0.996 & 657.5 & 0.996 \\
\hline J & 69.24 & 0.986 & 3023.2 & 0.995 \\
\hline K & 0.23 & 0.953 & 27.1 & 0.959 \\
\hline
\end{tabular}

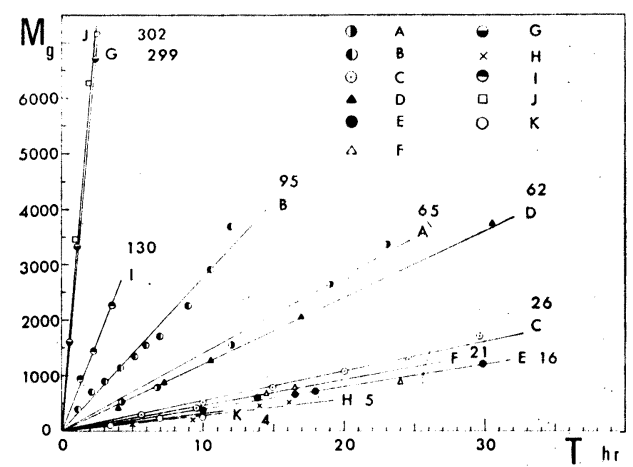

Fig. 4 Relations between amount of wear of rippertip $M$ and ripping operation time $T$ (Numbers show $\sigma_{c}$ values).

of maximum weighing $20 \mathrm{~kg}$, sensitivity $1 \mathrm{~g}$ was used. In spite of the same rippertip, it is cleared that the characteristics of variation of wear amount of tip is dependent upon the properties of rock mass. The relations between the amount of wear of tip $M$ and the ripping operation time $T$ seem to be able to approximate some linear equations $M=$ $b T$ for each site respectively. The most probable value of coefficient " $b$ " and coefficient of correlation " $r_{b}$ " are shown in Table 2 .

\section{CHARACTERISTICS OF SHAPE VARI- ATION OF TIP}

As mentioned above, the higher the index of 
rock mass strength for wear, the greater the wear length of tip increases due to impact load at the time of excavation. On the other hand, since almost all rock masses of small index of rock mass strength for wear are composed of rock materials of comparatively small abrasive strength ${ }^{9)}$, it is cleared that the wear length of pointed end of tip decreases relatively while the amount of wear of side wall of tip increases. That is, the compressive strength of rock materials of comparatively small abrasive strength are relatively small, then any impact load does not occur on the pointed end of tip. And, the high contact pressure acted on the pointed end of tip beyond the abrasive strength break down rock material instead of metal material, while the low contact pressure acted on the side wall of tip under the abrasive strength is contributed to wear metal material ${ }^{3)}$.

As representative examples, two kinds of shape variation of tip tested at site $A$ and $G$ are explain-

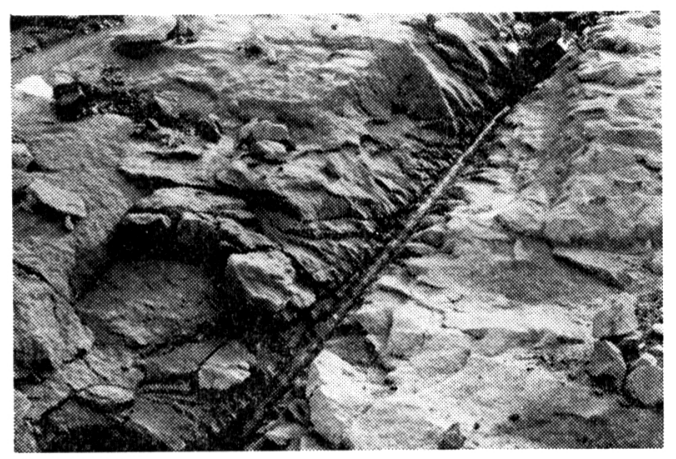

Photo. 1 General view of site during ripping operation (Site A).

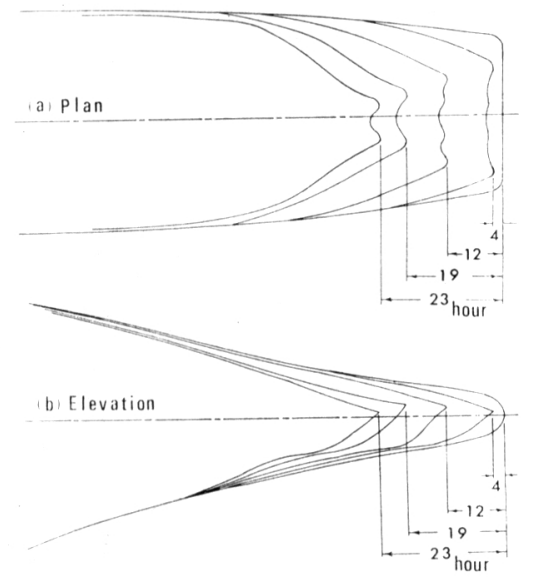

Fig. 5 Shape variation of tip due to wear for some ripping operation time (Site A). ed. Test site A is selected as impact wear of tip is predominant.

The ripping operation site $\mathrm{A}$ is formed of clay slate consisted of quartz and plagioclase only which has comparatively small abrasive strength. Photo. 1 shows the state of rock mass in this site A after some ripping operations by use of 2 tips, and several grooves of the trace of tip are clearly observed on the surface of rock mass. The occurrence of these grooves is generally observed in this kind of rock mass and is also observed in other operation site H. Fig. 5 (a) (b) show the plan and

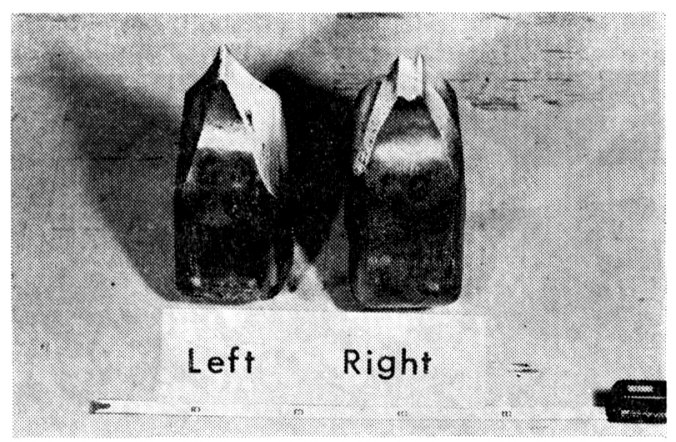

(a)

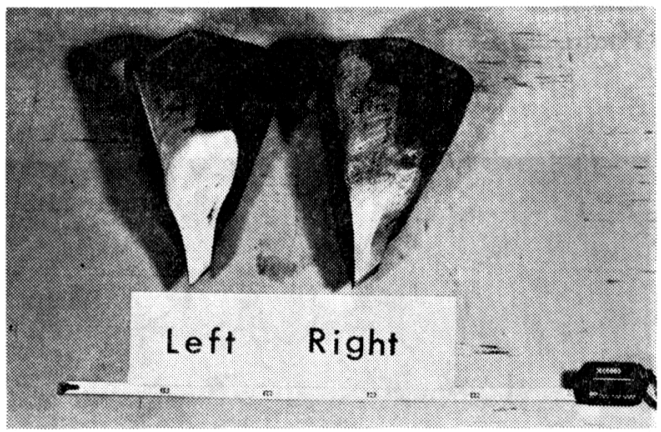

( b )

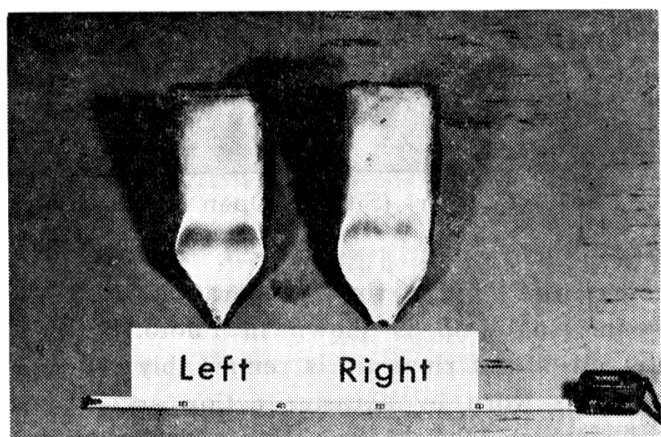

(c)

Photo. 2 Examples of worn shape of rippertip (Site A). 
elevation of shape variation of tip in this site A, which are traced respectively for each operation time. The numerals in this figure mean the ripping operation time expressed by hour. Photo. 2 (a) (b) (c) show the interesting shapes of tip which are worn out in this ripping operation site A. From these examples, it is considered that the ripperbility for these rock masses of comparatively small abrasive strength of rock does not practically decrease with the progress of wear of tip, because the wear of side parts of tip is more remarkable than that of end pointed parts of tip and the shape of end pointed parts becomes sharp and slender.

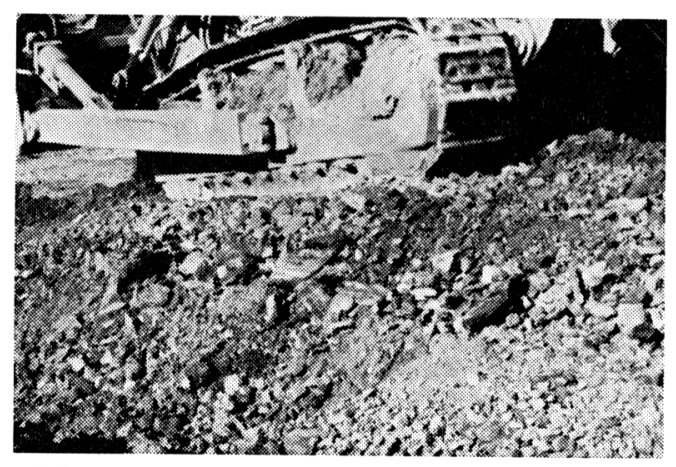

Photo. 3 General view of site during ripping operation (Site G).

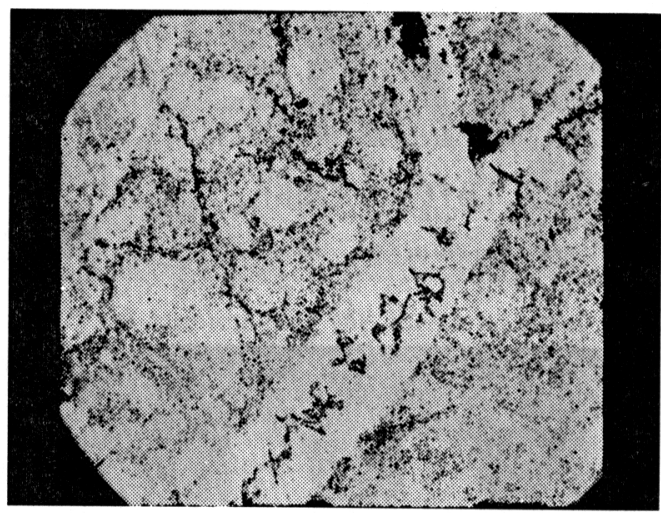

Photo. 4 Chert (Site G, Open Nikol $\times 59$ ).

Next, the state of ripping operation at site $G$ by use of single tip is shown in Photo. 3. In this site, the life of rippertip is remarkably short since the tip is worn by abrasive action accompanying with impact load at the time of excavation for comparatively high fissurred chert. Photo. 4 shows the polarization microphotograph of the chert in this site G. The main rock forming minearals consist of groundmass and some quartz grains, and the rock mass is formed of sedimentary rock of single rock forming mineral of quartz. Fig. 6 (a) (b) show the plan and elevation of shape variation of tip in site $G$, which are traced respectively for each operation time. The numerals in this figure mean the ripping operation time expressed by minute. Photo. 5 (a) (b) show the shape of tip which is worn out in this ripping operation site. From these figures and photographs, it is cleared that the ripperbility for these hard rock mass decreases gradually with the progress of wear of tip because the wear of end pointed parts of tip is more remarkable than that of side parts of tip and, as a whole, the shape of end pointed parts of tip becomes round.

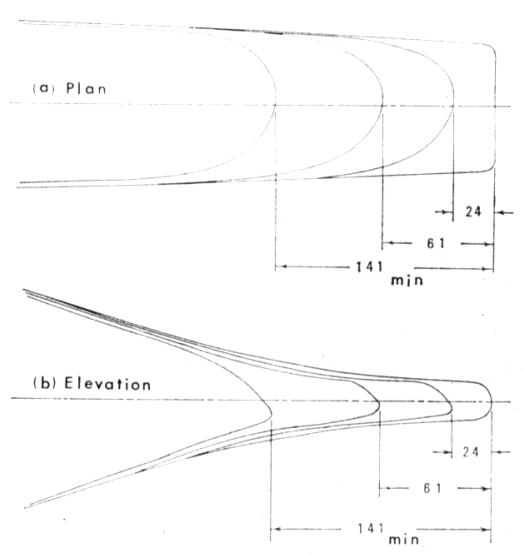

Fig. 6 Shape variation of tip due to wear for some ripping operation time (Site G).

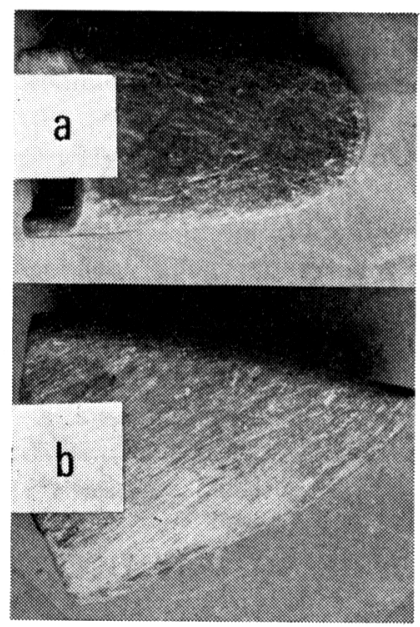

Photo. 5 Example of worn shape of rippertip (Site G). (a) plan (b) elevation 


\section{ESTIMATION OF LIFE OF TIP DUE TO WEAR}

As previously mentioned, the index of rock mass strength for wear is largely influenced by the porosity of rock mass. For the purpose of analyzing this relation, the Fourmaintraux Diagram is modified in relation to the ratio of $I Q_{2}$ to $I Q_{1}$ as shown in right hand side of Fig. 7. This ratio $I Q_{2} / I Q_{1}$ is considered as $V_{2} / V_{1}$. And this "Coefficient of damage of rock mass" $V_{2} / V_{1}$ means the square root of $1-C_{r}$. The relations of the ratio $I Q_{2} / I Q_{1}$ and total porosity $n_{2}$ of fissured rock mass $\mathrm{A}, \mathrm{B}, \mathrm{C}$, $\cdots$, and $\mathrm{K}$ are plotted in this figure, from which the coefficient of damage of rock mass, porosity of fissure, and porosity of pore of given rock mass are easy to understand at a glance.
$L=a T$. For almost all the cases, the tip should be exchanged into another new article when the wear length of pointed end of tip $L$ reaches 160 $\mathrm{mm}$. Then, assuming that the critical wear length $L_{c}$ equals to $160 \mathrm{~mm}$, the critical life of tip $T_{c}$ can be calculated by $160 / a$. Fig. 8 shows the relations between the critical life of tip $T_{c}$ calculated from the measured wear length of pointed end of tip and index of rock mass strength for wear $\sigma_{c}$, which are plotted on logarithmic scale. The experimental equation obtained is as follows;

$$
T_{c}=6.40 \times 10^{3} \sigma_{c}^{-1.26} \quad(r=0.904)
$$

It is cleared that the coefficient of correlation is relatively low value, and their data are fairly scattered.

On the other hand, from previous Fig. 4, the relation between amount of wear of tip $M$ and rip-

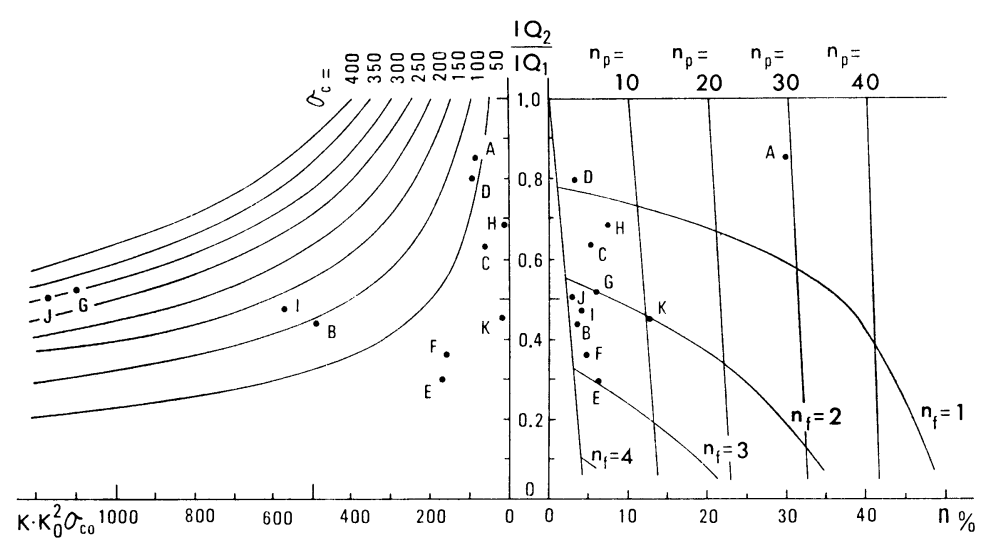

Fig. 7 Relations between porosity of rock mass $n$ and ratio of rock quality index $I Q_{2} / I Q_{1}$ modified from Fourmaintraux Diagram, and contour lines of rock mass strength for wear $\sigma_{c}$.

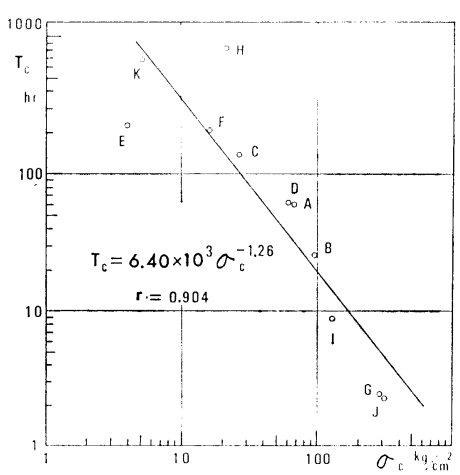

Fig. 8 Relations between critical wear life of rippertip $T_{c}$ and rock mass strength for wear $\sigma_{c}$, calculated from measurements of wear length of tip.
Then, the contour lines of index of rock mass strength for wear are shown in the left hand side of Fig. 7 which is related between the ratio $I Q_{2} / I Q_{1}$ concerning the porosity of rock mass and the other factors $K \cdot K_{0}^{2} \sigma_{c o}$. And, the points $\mathrm{A}, \mathrm{B}, \mathrm{C}, \cdots$, and $\mathrm{K}$ are plotted from their in-situ and laboratory test results respectively. From these considerations, it is cleared that the relations between porosity or coefficient of crack of rock mass and $K \cdot K_{0}^{2} \sigma_{c o}$ value have a significant meaning for the same index of rock mass strength for wear to understand the properties of rock mass and the life of tip due to wear.

From previous Fig. 3, the relation between wear length of pointed end of tip $L$ and ripping operation time $T$ is generally expressed by linear equation ping operation time $T$ is generally expressed by linear equation $M=b T$. For many cases, the tip should be exchanged into another new article when the amount of wear $M$ reaches $7000 \mathrm{~g}$. Then, assuming that the critical amount of wear $M_{c}$ equals to $7000 \mathrm{~g}$, the critical life of tip $T_{c}$ can be calculated by $7000 / b$. Fig. 9 shows the relations between the critical life of tip $T_{c}$ calculated from the measured amount of wear of tip and index of rock mass strength for wear $\sigma_{c}$, which are plotted on logarithmic scale. These relations are shown by two straight line folded together at the index of rock mass strength for wear of about $43 \mathrm{~kg} / \mathrm{cm}^{2}$, which divides the rock mass into light wear zone and heavy wear zone. The experimental equations obtained are as follows; 


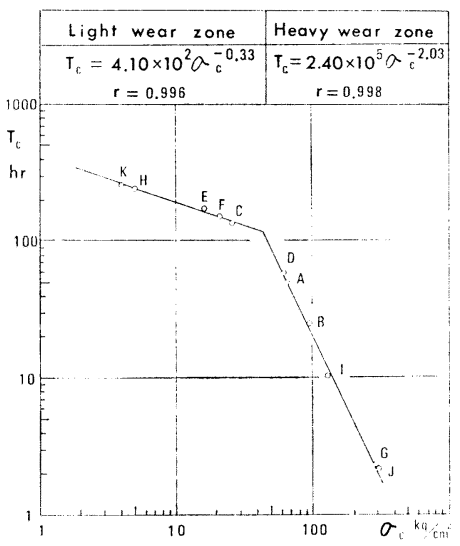

Fig. 9 Relations between critical wear life of rippertip $T_{c}$ and rock mass strength for wear $\sigma_{c}$, calculated from measurements of amount of wear of tip.

For light wear zone $\left(0<\sigma_{c} \leqq 43 \mathrm{~kg} / \mathrm{cm}^{2}\right)$

$$
T_{c}=4.10 \times 10^{2} \sigma_{c}^{-0.33} \quad(r=0.996)
$$

For heavy wear zone $\left(\sigma_{c}>43 \mathrm{~kg} / \mathrm{cm}^{2}\right)$

$$
T_{c}=2.40 \times 10^{5} \sigma_{c}^{-2.03} \quad(r=0.998)
$$

It is cleared that the coefficients of correlation are remarkably high value, and these above equations are most useful for estimating the life of rippertip due to wear. And, this folded point seems to show that the plastic yielding of metal material of tip due to abrasive wear begins at this point of index of rock mass strength.

And, Eqs. (5) and (6) may be more higher appreciated rather than Eq. (4) as equations which estimate the wear life of rippertip, because of high coefficients of correlations. For estimating the wear life of tip, the in-situ test method of measuring amount of wear of tip is more valuable than that of measuring wear length of tip from the point of view of total energies of ripping operation work. Furthermore, the wear life of tip estimated from the in-situ test results shown in Fig. 4 agrees well with actual wear life of another tip measured at each site for even light wear zone. That is, the assumption of linear equation of $M=b T$ become clear to be right for the test method of measuring amount of wear of tip, while the in-situ test results do not reach the critical amount of wear for light wear zone.

\section{CONCLUSION}

For estimating the wear life of rippertip in mechanical exacvation of comparatively hard rock mass, many new informations are obtained from in-situ wear tests as follows;

(1) The characteristics of rock mass for wear of rippertip can be expressed by "Index of Rock Mass Strength for Wear" which is calculated by uniaxial compressive strength for non-fissured rock sample, coefficient of crack of rock mass, contents of quartz and hard rock forming minerals, and other factors related to wear of tip.

(2) The amount of wear and the wear length of tip increase approximately with linear relationship to the ripping operation time. Each slope varies respectively according to the index of rock mass strength for wear.

(3) For the rock mass which both the index of rock mass strength for wear and the coefficient of crack of rock mass are comparatively small, and the content of hard rock forming minerals is relatively high, the wear of side parts of tip progresses more rapidly rather than that of pointed end of tip. On the other hand, for high index of rock mass strength for wear, the wear of pointed end of tip progresses more rapidly rather than that of side parts of tip.

(4) The ripperbility of rock mass are expressed by index of rock mass strength for wear, and in more details, the relation between porosity or coefficient of crack of rock mass and the products of uniaxial compressive strength, contents of hard rock minerals and so on, are shown in modified Fourmaintraux Diagram.

(5) The wear life of rippertip can be estimated by the function of index of rock mass strength for wear, and the in-situ test method of measuring amount of wear of tip is more valuable than that of measuring wear length of tip for estimating the life of tip due to wear.

These field test results may be expected in future to be useful for the design of initial shape of tip for several kinds of rock mass, the manufacture of tip which controlled the wear resistance of all parts of tip, estimating the wear life of tip for the given ripping operation site, and the rational construction management for mechanical excavation of rock mass.

The authors wish to express their sincere thanks to several collaborators who work together and offer the ripping operation sites.

\section{REFERENCES}

1) K. Adachi: Excavation of rock mass, Soils and Foundations, 21-3, 181 (1973), pp. 59-65. (In Japanese)

2) S. Hata, T. Muro and M. Kaneuji: Characteristics of shape variation of rippertip, Proc. 
29th Annual Meeting of JSCE, Vol. 3, (1974), pp. 324-325. (In Japanese)

3) T. Muro: Characteristics of shape variation of rippertip by wear and abrasiveness of rock -from laboratory test-, Proc. of the JSCE. unpublished.

4) T. Muro: Characteristics of shape variation of rippertip-from field test-, Memoirs of the Faculty of Engineering, Fukui University, Vol. 25, No. 1, (1977), pp. 1-12.

5) T. Muro: Correlations between several properties of rock specimens, Memoirs of the Faculty of Engineering, Fukui University, Vol. 24, No. 1, (1976), pp. 1-18.

6) S. Okuzono: Failure of cut slopes and slope gradient, Soils and Foundations, 20-2, 168 (1972), pp. 33-39. (In Japanese)

7) Fourmaintraux, D: Quantification des discontinuités des roches et des massifs rocheux, Rock Mechanics, Vol. 7, No. 2, (1975), pp. 83100.

8) B. Kujundžić and B. Čolić: Rock mass mechanical Characteristics in an Opencut at Bor Copper Mine, Rock Mechanics, Vol. 8, No. 3, (1976), pp. 153-167.

9) T. Muro, T. Nakamura: Influence of characteristics of rock on wear of rippertip, Proc. 30th Annual Meeting of JSCE, Vol. 3, (1975), pp. 518-519. (In Japanese)

(Received January 17, 1977) 